\title{
Strategies of drug companies to optimize the sales of their psychiatric drugs Robert Whitaker
}

Address: None, 19 Rockingham St., Cambridge, MA 02139, USA

from WPA Thematic Conference. Coercive Treatment in Psychiatry: A Comprehensive Review

Dresden, Germany. 6-8 June 2007

Published: 19 December 2007

BMC Psychiatry 2007, 7(Suppl I):S90 doi:10.1 I86/147I-244X-7-SI-S90

This abstract is available from: http://www.biomedcentral.com//47I-244X/7/SI/S90

(C) 2007 Whitaker; licensee BioMed Central Ltd.

The rise and fall of the "atypical" neuroleptics: a case study in how the pharmaceutical industry hypes its products. When the atypical antipsychotics were introduced into the market in the early 1990s (most notably risperidone and olanzapine), they were presented to the public as "breakthrough medications" that were both more effective and safer than the standard neuroleptics (like chlorpromazine and haloperidol). Now we know that the atypicals are no more effective than the older drugs, and are perhaps even more problematic, in terms of their side effects. This presentation will look at how the pharmaceutical companies created the initial story of "breakthrough" medications, even though the clinical trial data they submitted to the FDA in the early 1990s revealed, in fact, that the drugs were no more effective than the older ones and caused a wide range of troubling side effects. 